\title{
Use and feasibility of delayed prescribing for respiratory tract infections: A questionnaire survey
}

Sigurd Høye ${ }^{1 *}$, Jan C Frich ${ }^{2}$ and Morten Lindbæk

\begin{abstract}
Background: Delayed prescribing of antibiotics for respiratory tract infections (RTIs) lowers the amount of antibiotics consumed. Several national treatment guidelines on RTIs recommend the strategy. When advocating treatment innovations, the feasibility and credibility of the innovation must be taken into account. The objective of this study was to explore GPs use and patients uptake of wait-and-see prescriptions for RTIs, and to investigate the feasibility of the strategy from GPs' and patients' perspectives.

Methods: Questionnaire survey among Norwegian GPs issuing and patients receiving a wait-and-see-prescription for RTIs. Patients reported symptoms, confidence and antibiotics consumption, GPs reported diagnoses, reason for issuing a wait-and-see-prescription and their opinion about the method.

Results: 304 response pairs from consultations with 49 GPs were received. The patient response rate was 80\%. The most common diagnosis for the GPs to issue a wait-and-see prescription was sinusitis (33\%) and otitis (21\%). $46 \%$ of the patients reported to consume the antibiotics. When adjusted for other factors, the diagnosis did not predict antibiotic consumption, but both being 16 years or more $(p=0,006)$ and reporting to have a fever $(p=0,012)$ doubled the odds of antibiotic consumption, while feeling very ill more than quadrupled the odds $(p=0,002)$. In 210 cases (69\%), the GP found delayed prescribing a very reasonable strategy, and 270 patients (89\%) would prefer to receive a wait-and-see prescription in a similar situation in the future. The GPs found delayed prescribing very reasonable most frequently in cases of sinusitis $(79 \%, p=0,007)$ and least frequently in cases of lower RTIs $(49 \%, p$ $=0,002$ ).
\end{abstract}

Conclusion: Most patients and GPs are satisfied with the delayed prescribing strategy. The patients' age, symptoms and malaise are more important than the diagnosis in predicting antibiotic consumption. The GP's view of the method as a reasonable approach depends on the patient's diagnosis. In our setting, delayed prescribing seems to be a feasible strategy, especially in cases of sinusitis and otitis. Educational efforts to promote delayed prescribing in similar settings should focus on these diagnoses.

\section{Background}

General practitioners (GPs) issue more than $90 \%$ of antibiotic prescriptions in Norway, and about $60 \%$ of these are issued for common respiratory tract infections (RTIs) [1]. RTIs are often self-limiting, and antibiotics have a modest role in the treatment of such conditions [2]. Unnecessary use of antibiotics is a global concern,

\footnotetext{
* Correspondence: sigurd.hoye@medisin.uio.no

${ }^{1}$ Antibiotic Center for Primary Care, Department of General Practice, Institute of Health and Society, University of Oslo, P.O.Box 1130 Blindern, N-0318 Oslo, Norway

Full list of author information is available at the end of the article
}

as it leads to antibiotic resistance, adverse drug reactions, and medicalization of self-limiting disease. Antibiotic prescription rates are relatively low in Norway and other Northern European countries [3], but a recent Norwegian prescription study found that there still is room for improvement [4].

Much effort has been put into developing strategies to reduce over-consumption of antibiotics for RTIs in general practice, and randomized controlled trials have provided evidence for delayed prescribing as an effective strategy. Reported pick up rates for wait-and-see prescriptions varies from $24-38 \%$ (otitis media) [5,6], 31\%

\section{Biomed Central}


(sore throat) [7], 20 - 45\% (cough) [8,9], to $48 \%$ (common cold) [10]. The safety of the method seems to be good, and there is probably no increase in complication rates, but a longer duration of certain symptoms in some studies [11].

It has been argued that delaying antibiotics has little advantage over avoiding them where it is safe to do so [11]. However, the question regarding safety in handling RTIs is not clear cut, and factors like physician insecurity, patient demands and work load lead GPs to prescribe antibiotics without a good medical indication [12]. GPs experience numerous situations where they find delayed prescribing reasonable [13]. Hence, delayed prescribing might have an important place in the management of RTIs [14]. The strategy is recommended in several national treatment guidelines on RTIs in general practice [15-17], and it is part of the intervention in quality improvement studies on appropriate antibiotics prescribing [18-20].

Delayed prescribing is not universally endorsed by GPs $[13,21]$, though patients seem to be confident and satisfied with wait-and-see prescriptions $[7,22]$. When advocating treatment innovations to improve quality of care, the feasibility and credibility of the innovation must be taken into account [23]. There is a lack of knowledge on if, and in which situations, GPs find delayed prescribing a reasonable approach, and in which situations GPs choose to use the strategy.

The aim of this study is to explore GPs use and patients uptake of wait-and-see prescriptions for RTIs, and to investigate the feasibility of the strategy from GPs' and patients' perspective.

The terms "delayed prescribing" and "wait-and-see prescription" are used synonymously in the literature. In this paper we use "delayed prescribing" for the strategy, and "wait-and-see prescription" denotes the prescription itself.

\section{Methods}

\section{Subjects and setting}

We translated and adopted a questionnaire on patients' response to delayed prescription used in a previous study [22], and developed a questionnaire on GPs reasons for issuing wait-and-see prescriptions.

The study was conducted as a part of the Prescription Peer Academic Detailing (Rx-PAD) Study, a cluster-randomized educational intervention study in Norwegian general practice with the aim of improving antibiotic prescribing in respiratory tract infections [18]. The elements of the intervention were educational outreach visits to the participants' continuing medical education groups comprising presentation and discussion of evidence-based antibiotics prescribing for RTIs, collection of individual prescription data, audit based on individual feedback reports, as well as a one-day regional seminar. As part of the seminar, one of the authors $(\mathrm{SH})$ gave a lecture on the evidence regarding delayed prescribing, and invited the GPs to recruit patients to the present study. 58 GPs agreed to participate. In addition, 16 GPs affiliated to the Department of General Practice, University of Oslo, were given the same lecture, and agreed to participate (Figure 1)

Eligible patients were those of any age who consulted the GP for a RTI, and to whom the GP found it appropriate to offer a wait-and-see prescription. In the course of the consultation, the GP handed the patient an antibiotic prescription together with a patient questionnaire, a consent form, an information leaflet and a prestamped envelope. The patient was instructed to wait for a certain amount of time, chosen by the GP, before deciding whether to take the antibiotics or not. The questionnaire was to be filled once the patient had made this decision. After the consultation, the doctor filled in the GP questionnaire. Patients were rewarded with a scratchcard upon responding, while the GP would receive a gift card for a CD when they had recruited 10 patients. Recruitment took place during April 2006 through June 2008.

The Regional Committee for Research Ethics in Oslo, Norway, approved the study (S-05272).

\section{Statistical analysis}

Chi square test was used to compare those patients who reported to consume antibiotics and those who did not, with regard to both patient factors (demographic characteristics, presenting symptoms, expectations, confidence in deciding whether to use the prescription) and GP factors (diagnose, reason for giving wait-and-see prescription, reasonableness, and impression of expectations and use of the prescription). Logistic regression analysis was performed with the dependent variable being whether the patient reported to consume the antibiotics or not. Further, we compared cases where the GP found delayed prescribing very reasonable and cases where where the GP did not. A significance level of 5\% was applied. Analyses were performed using SPSS 14 and 18 .

\section{Material}

Out of a total of 68 GPs, 49 (72\%) recruited on average 8.5 patients each (median 6; span 1-34). 19 (28\%) GPs recruited no patients. We received 413 responses from GPs and 332 responses from patients. Five patients informed that they did not want to participate, and consequently we removed the corresponding GPs responses. For five of the patient responses, we did not receive a corresponding GPs response, resulting in 327 response pairs and a patient response rate of $80 \%$. 


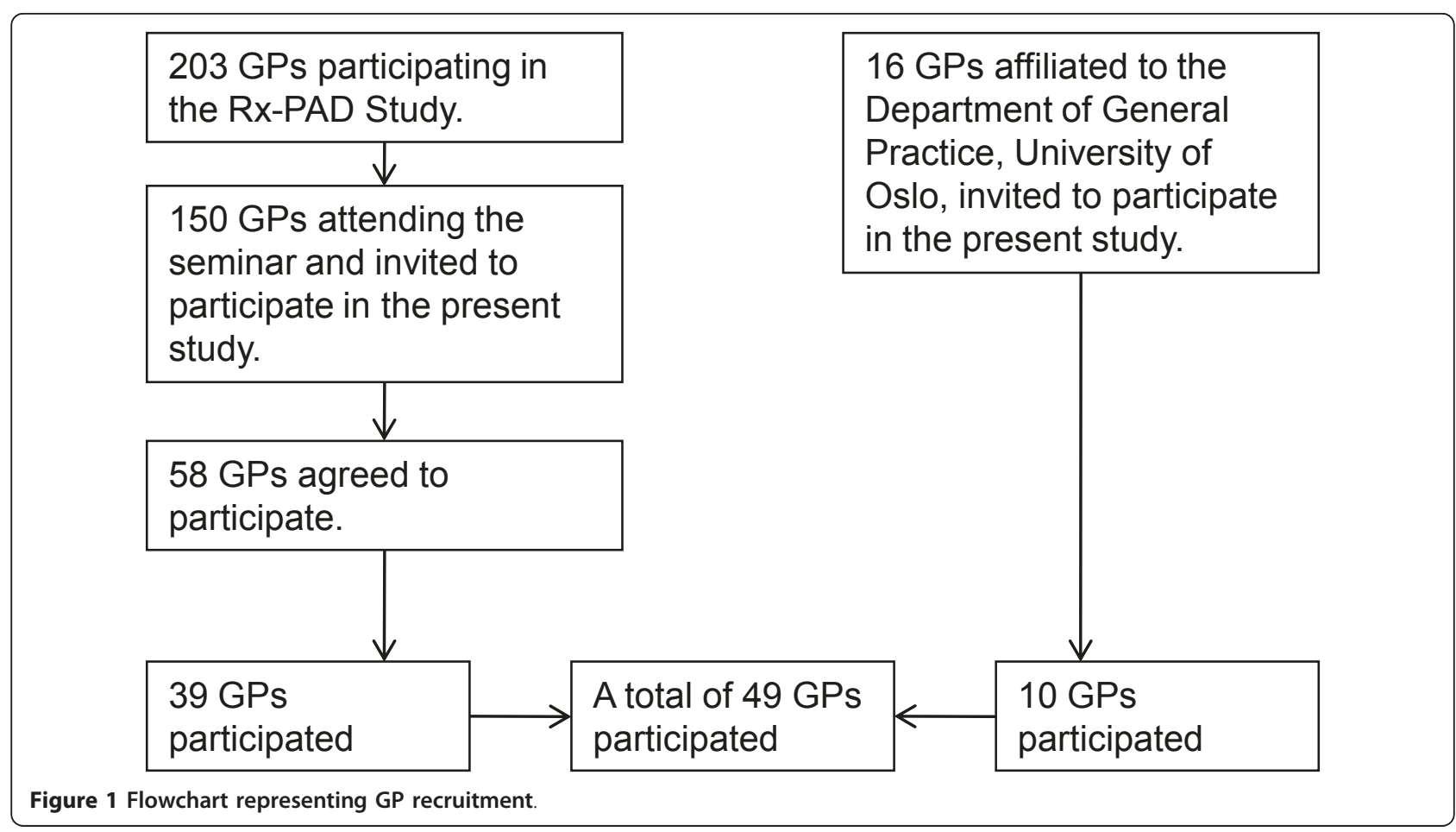

17 response pairs were excluded because the GPs had included patients who were treated for other conditions than RTIs, and an additional six response pairs were excluded because the patients failed to answer whether they had taken antibiotics. 304 response pairs remained for analysis.

We grouped diagnoses according to previouos studies on RTIs [1,24]. Table 1 displays the characteristics of the participating patients and GPs.

Table 1 Characteristics of participating patients and GPs

\begin{tabular}{|c|c|c|}
\hline & $\mathrm{n}$ & (\%) \\
\hline Patients & 304 & $(100)$ \\
\hline \multicolumn{3}{|l|}{ Gender } \\
\hline Female & 204 & (67) \\
\hline Male & 100 & (33) \\
\hline \multicolumn{3}{|l|}{ Grouped age (years) } \\
\hline Less than 16 & 100 & (33) \\
\hline $16-59$ & 180 & (59) \\
\hline 60 and over & 24 & (8) \\
\hline GPS & 49 & $(100)$ \\
\hline \multicolumn{3}{|l|}{ Gender } \\
\hline Female & 13 & (27) \\
\hline Male & 36 & (73) \\
\hline \multicolumn{3}{|l|}{ Delayed prescriptions issued } \\
\hline 1-4 prescriptions & 19 & (39) \\
\hline 5-9 prescriptions & 12 & (24) \\
\hline 10-19 prescriptions & 13 & (27) \\
\hline More than 20 prescriptions & 5 & (10) \\
\hline
\end{tabular}

\section{Results}

Comparison of responders and non-responders

Of the 81 non-responding patients, there were significantly more men (47\% vs $33 \%)$ and more patients with upper RTIs (34\% vs 20\%), compared to the group of responders.

\section{Delayed prescribing - when and why}

Table 2 shows the diagnoses given by the GPs when issuing a wait-and-see prescription, and the diagnose groups used in the further analysis. In comparison with a reference material of antibiotic prescribing for respiratory tract infections in a Norwegian county during two winter months in 2003, our material shows an overrepresentation of sinusitis $(33,2 \%$ vs $14,6 \%)$ and otitis $(21,4 \%$ vs $9,1 \%)$, and an underrepresentation of lower RTI (13,5\% vs $28,5 \%)$ and tonsillitis (7,9\% vs $16,8 \%)$.

The majority (58\%) of the children given a wait-andsee-prescription had otitis, while the majority (49\%) of adults had sinusitis, and the elderly had lower RTI (46\%). Patients with the diagnosis of upper RTI reported feeling more ill $(\mathrm{p}=0,009)$, and patients with tonsillitis felt less ill $(p=0,04)$ compared to patients with other diagnoses.

The GPs reported that they issued wait-and-see prescriptions mainly because of uncertainty about the indication for antibiotics (211 cases, 69\%) or uncertainty about the diagnose (32 cases, 11\%). (See also table 4). Difficulties connected to follow up was given as reason in 29 cases (10\%), and disagreement with the patient on 
Table 2 Diagnoses where GPs issued delayed prescription, compared to a reference material of antibiotic prescriptions for respiratory tract infections

\begin{tabular}{|c|c|c|c|c|c|c|c|}
\hline \multirow[b]{2}{*}{ Diagnose group } & \multirow[b]{2}{*}{ Diagnose } & \multirow[b]{2}{*}{ ICPC-2 code } & \multirow[b]{2}{*}{$\mathrm{n}$} & \multirow[b]{2}{*}{$\%$} & \multirow[b]{2}{*}{$(95 \% \mathrm{Cl})$} & \multicolumn{2}{|c|}{ Reference (Vestfold study) } \\
\hline & & & & & & $\%$ & $(95 \% \mathrm{Cl})$ \\
\hline \multicolumn{2}{|c|}{ Upper respiratory tract symptoms and infections } & & 60 & 19,7 & $(15,3-24,2)$ & 21,3 & $(20,0-22,6)$ \\
\hline & Cough & r05 & 6 & & & & \\
\hline & Sinus symptom/complaint & r09 & 7 & & & & \\
\hline & Throat symptom/complaint & r21 & 4 & & & & \\
\hline & Upper respiratory infection acute & r74 & 43 & & & & \\
\hline \multicolumn{2}{|c|}{ Lower respiratory tract infections } & & 41 & 13,5 & $(9,7-17,3)$ & 28,5 & $(27,1-29,9)$ \\
\hline & Acute bronchitis/bronchiolitis & r78 & 36 & & & & \\
\hline & Pneumonia & r81 & 4 & & & & \\
\hline & COPD & r95 & 1 & & & & \\
\hline \multirow[t]{5}{*}{ Ear infections } & & & 65 & 21,4 & $(16,8-26,0)$ & 9,1 & $(8,2-10,0)$ \\
\hline & Ear pain/earache & h01 & 1 & & & & \\
\hline & Ear discharge & h04 & 1 & & & & \\
\hline & Ear symptom/complaint other & h29 & 1 & & & & \\
\hline & Acute otitis media/myringitis & h71 & 62 & & & & \\
\hline \multirow[t]{2}{*}{ Sinusitis } & & & 101 & 33,2 & $(27,9-38,5)$ & 14,6 & $(13,5-15,7)$ \\
\hline & Sinusitis acute/chronic & r75 & 101 & & & & \\
\hline \multirow[t]{3}{*}{ Acute tonsillitis } & & & 24 & 7,9 & $(4,9-10,9)$ & 16,8 & $(15,7-18,0)$ \\
\hline & Strep throat & $\mathrm{r} 72$ & 5 & & & & \\
\hline & Tonsillitis acute & r76 & 19 & & & & \\
\hline \multicolumn{2}{|c|}{ Other respiratory diagnoses } & & 13 & 4,3 & $(2,0-6,6)$ & 9,7 & $(8,8-10,6)$ \\
\hline & Laryngitis/tracheitis acute & r77 & 4 & & & & \\
\hline & Influenza & r80 & 7 & & & & \\
\hline & Respiratory infection other & r83 & 2 & & & & \\
\hline
\end{tabular}

the need for antibiotics in 12 cases (4\%). In 44 cases (14\%), the GP reported "Other reasons", and in 34 of these cases, this was the only explanation for issuing the wait-and-see prescription. "Other reasons" were in all but one case described as clinical or therapeutic peculiarities in the specific situation (eg. mild symptoms, pregnancy, short duration of symptoms, other treatment started).

\section{Factors associated with the decision to consume antibiotics}

141 (46\%) of the patients reported to consume the antibiotics. Diagnoses and patients' factors associated with consumption of antibiotics are presented in table 3 . There were no statistically significant differences between those who reported to have consumed antibiotics and those who did not in respect of their gender or their educational level.

Patients diagnosed with an ear infection were less likely to consume antibiotics. Patients younger than 16 years were less likely to consume antibiotics $(p=0,04)$. When reporting to have fever, patients were more likely to consume antibiotics $(\mathrm{p}=0,012)$. Also, a higher number of reported symptoms $(p=0,024)$ and more malaise $(\mathrm{p}=0,012)$ made patients more likely to consume antibiotics.

The prognostic variables in table 3 resulting in a pvalue of 0,25 or less were included in a logistic regression analysis, together with the background characteristics age, gender and educational level, the dependent variable being whether the patient reported to consume the antibiotics or not (Table 4). Symptom sum was not included, as this variable was closely correlated to, and also included, the individual symptoms. Four factors were significantly associated with consuming antibiotics. Having a fever, reporting to be very ill and being of older age increased the odds, while a nasal congestion decreased the odds of consuming antibiotics.

When asked whether they thought the patient would take the antibiotics, the GPs answered yes in 51 (17\%) of the cases, no in 131 (43\%) of the cases and that they were uncertain in 122 (40\%) of the cases. The GPs' presumption was slightly correlated with the patients' reported action ( $p=0,025$, correlation coefficient 0,166 ).

\section{Feasibility of delayed prescribing}

$262(86 \%)$ out of the 304 patients stated that they felt confident in deciding whether to use the prescription, 
Table 3 Patients' characteristics, presenting symptoms and expectations, by consumption of antibiotics

\begin{tabular}{|c|c|c|c|c|c|c|c|c|}
\hline Grouped age (years) $n=304$ & \multicolumn{2}{|c|}{$\begin{array}{c}\text { Total } \\
(\%)\end{array}$} & \multicolumn{2}{|c|}{$\begin{array}{l}\text { Patients who took } \\
\text { antibiotics }(\%)^{\mathrm{a}} \\
(\mathrm{n}=141)\end{array}$} & \multicolumn{2}{|c|}{$\begin{array}{l}\text { Patients who did not } \\
\text { take antibiotics }(\%)^{\mathrm{a}} \\
(\mathrm{n}=163)\end{array}$} & Pick up rate $\%$ & P-value ${ }^{b}$ \\
\hline Less than 16 & 100 & (33) & 38 & (27) & 62 & (38) & 38 & $0,04^{*}$ \\
\hline $16-59$ & 180 & $(59)$ & 90 & (64) & 90 & $(55)$ & 50 & 0,13 \\
\hline 60 and over & 24 & (8) & 13 & (9) & 11 & (7) & 54 & 0,43 \\
\hline \multicolumn{9}{|l|}{ Gender $n=304$} \\
\hline Female & 204 & $(67)$ & 95 & (67) & 109 & $(67)$ & 47 & 0,93 \\
\hline Male & 100 & (33) & 46 & (33) & 54 & (33) & 46 & \\
\hline \multicolumn{9}{|l|}{ Highest education $n=302(140 / 162)$} \\
\hline Basic education (7-9 years) & 34 & $(11)$ & 15 & (11) & 19 & (12) & 44 & 0,78 \\
\hline High school (10-12 years) & 105 & $(35)$ & 50 & (36) & 55 & (34) & 48 & 0,75 \\
\hline College/university (>12 years) & 163 & $(54)$ & 75 & (53) & 88 & $(54)$ & 46 & 0,9 \\
\hline \multicolumn{9}{|l|}{ Presenting symptoms $n=303(141 / 162)$} \\
\hline Sore throat & 101 & (33) & 52 & (37) & 49 & (30) & 51 & 0,21 \\
\hline Earache & 94 & $(31)$ & 40 & (28) & 54 & (33) & 43 & 0,37 \\
\hline Cough & 124 & $(41)$ & 63 & (45) & 61 & (37) & 51 & 0,2 \\
\hline Fever & 111 & $(37)$ & 62 & (44) & 49 & (30) & 56 & $0,012^{*}$ \\
\hline Sinus pain & 118 & (39) & 56 & (40) & 62 & (38) & 47 & 0,76 \\
\hline Muscular aches & 32 & $(11)$ & 17 & (12) & 15 & (9) & 53 & 0,42 \\
\hline Runny nose & 49 & $(16)$ & 22 & (16) & 27 & (17) & 45 & 0,82 \\
\hline Nasal congestion & 94 & $(31)$ & 39 & (28) & 55 & (34) & 41 & 0,25 \\
\hline Malaise & 72 & $(24)$ & 38 & (27) & 34 & (21) & 53 & 0,21 \\
\hline Wheezing/shortness of breath & 61 & $(20)$ & 31 & (22) & 30 & $(18)$ & 51 & 0,44 \\
\hline Other symptoms & 17 & (6) & 10 & (7) & 7 & (4) & 59 & 0,29 \\
\hline Sum symptoms & 873 & & 430 & case) & 443 & case) & & \\
\hline 1 symptom & 87 & $(29)$ & 30 & $(21)$ & 57 & (35) & 34 & $0,008^{*}$ \\
\hline 2-4 symptoms & 161 & $(53)$ & 81 & (57) & 80 & (49) & 50 & 0,15 \\
\hline More than 4 symptoms & 55 & $(18)$ & 30 & (21) & 25 & (15) & 55 & 0,18 \\
\hline \multicolumn{9}{|l|}{ Feeling ill n = 301 (139/162) } \\
\hline Very ill & 34 & $(11)$ & 24 & (17) & 10 & $(6)$ & 71 & $0,003^{*}$ \\
\hline Modestly ill & 193 & $(64)$ & 89 & (64) & 104 & (64) & 46 & 0,9 \\
\hline A bit ill & 74 & $(25)$ & 26 & (19) & 48 & (30) & 35 & $0,026^{*}$ \\
\hline \multicolumn{9}{|l|}{ Patient expectations $n=303(141 / 162)$} \\
\hline Antibiotic prescription & 157 & $(52)$ & 79 & (56) & 78 & (48) & 50 & 0,16 \\
\hline Other prescription & 44 & $(15)$ & 20 & (14) & 24 & (15) & 45 & 0,89 \\
\hline Advice & 51 & $(17)$ & 22 & (16) & 29 & (18) & 43 & 0,61 \\
\hline Tests & 144 & $(48)$ & 69 & (49) & 75 & (46) & 48 & 0,61 \\
\hline Referral & 9 & (3) & 3 & $(2)$ & 6 & $(4)$ & 33 & 0,43 \\
\hline Sicknote & 43 & $(14)$ & 24 & (17) & 19 & (12) & 56 & 0,18 \\
\hline No expectations & 50 & $(17)$ & 19 & (13) & 31 & (19) & 38 & 0,19 \\
\hline \multicolumn{9}{|l|}{ Diagnosis group $n=304$} \\
\hline Upper respiratory tract symptoms and infections & 60 & $(20)$ & 34 & (24) & 26 & (16) & 57 & 0,075 \\
\hline Lower respiratory tract infections & 41 & $(14)$ & 21 & (15) & 20 & (12) & 51 & 0,5 \\
\hline Ear infections & 65 & $(21)$ & 23 & (16) & 42 & (26) & 35 & $0,045^{*}$ \\
\hline Sinusitis & 101 & (33) & 47 & (33) & 54 & (33) & 47 & 0,97 \\
\hline Acute tonsillitis & 24 & (8) & 11 & (8) & 13 & (8) & 46 & 0,96 \\
\hline Other respiratory diagnoses & 13 & $(4)$ & 5 & (4) & 8 & (5) & 38 & 0,56 \\
\hline
\end{tabular}

a Percentages within the brackets are those within the patient group. b Pearson chi-square. 


\begin{tabular}{|c|c|c|c|c|}
\hline & \multicolumn{2}{|c|}{ Unadjusted } & \multicolumn{2}{|c|}{ Adjusted $^{a}$} \\
\hline & Odds ratio $(95 \% \mathrm{Cl})$ & P-value & Odds ratio $(95 \% \mathrm{Cl})$ & P-value \\
\hline \multicolumn{5}{|l|}{ Age (years) } \\
\hline Less than 16 & 1 & & 1 & \\
\hline $16-60$ & $1,63(0,99-2,69)$ & 0,054 & $2,21(1,25-3,92)$ & 0,006 \\
\hline 60 and over & $1,93(0,79-4,74)$ & 0,15 & $2,89(1,01-8,29)$ & 0,048 \\
\hline \multicolumn{5}{|l|}{ Sex } \\
\hline Male & 1 & & 1 & \\
\hline Female & $1,02(0,63-1,65)$ & 0,93 & $0,80(0,47-1,36)$ & 0,41 \\
\hline \multicolumn{5}{|l|}{ Highest education } \\
\hline Basic education (7-9 years) & 1 & & 1 & \\
\hline High school (-12 years) & $1,15(0,53-2,51)$ & 0,72 & $1,19(0,50-2,84)$ & 0,7 \\
\hline College/university (>12 years) & $1,08(0,51-2,27)$ & 0,84 & $1,33(0,58-3,05)$ & 0,5 \\
\hline \multicolumn{5}{|l|}{ Symptoms ${ }^{b}$} \\
\hline Sore throat & $1,36(0,84-2,19)$ & 0,21 & & \\
\hline Cough & $1,35(0,85-2,14)$ & 0,2 & & \\
\hline Fever & $1,83(1,14-2,93)$ & 0,012 & $1,94(1,15-3,27)$ & 0,012 \\
\hline Nasal congestion & $0,75(0,46-1,23)$ & 0,25 & $0,58(0,34-0,99)$ & 0,046 \\
\hline Malaise & $1,4(0,82-2,38)$ & 0,21 & & \\
\hline \multicolumn{5}{|l|}{ Feeling ill } \\
\hline A bit ill & 1 & & 1 & \\
\hline Modestly ill & $1,58(0,91-2,75)$ & 0,11 & $1,46(0,81-2,61)$ & 0,21 \\
\hline Very ill & $4,43(1,84-10,67)$ & 0,001 & $4,55(1,77-11,75)$ & 0,002 \\
\hline \multicolumn{5}{|l|}{ Patient expectations ${ }^{b}$} \\
\hline Antibiotic prescription & $1,39(0,88-2,18)$ & 0,16 & & \\
\hline Sicknote & $1,56(0,81-2,98)$ & 0,18 & & \\
\hline No expectations & $0,66(0,36-1,24)$ & 0,2 & & \\
\hline \multicolumn{5}{|l|}{ Diagnosis group } \\
\hline Sinusitis & 1 & & & \\
\hline Lower respiratory tract infections & $1,21(0,58-2,5)$ & 0,61 & & \\
\hline Otitis & $0,63(0,33-1,2)$ & 0,16 & & \\
\hline Upper respiratory tract symptoms and infections & $1,5(0,79-2,86)$ & 0,22 & & \\
\hline Tonsillitis & $0,97(0,4-2,38)$ & 0,95 & & \\
\hline Other & $0,72(0,22-2,35)$ & 0,58 & & \\
\hline
\end{tabular}

Odds ratio for reporting to consume the antibiotics.

a The odds ratios are adjusted for the background characteristics and for the other surviving variables in the model.

b The reference value is not having the spesific symptom/expectation.

12 patients (4\%) felt unconfident, and the remaining 30 patients $(10 \%)$ felt neither. There were no significant correlations between confidence and certain diagnosis or prescription pick up rate. 270 patients (89\%) would prefer to receive a wait-and-see prescription in a similar situation in the future, nine patients (3\%) would prefer not to be offered delayed prescribing, whereas 24 patients $(8 \%)$ were uncertain what they preferred. Patients with upper RTI did to a lesser extent wish for delayed prescribing in the future $(48 / 60,80 \%, \mathrm{p}=$ 0,016 ).

Out of the 163 patients stating not to consume the antibiotics, 64 (39\%) reported to have saved the prescription or the medication for later.
In 210 (69\%) of the cases, the GPs answered that they viewed delayed prescribing a very reasonable approach in the specific clinical setting. In 90 cases $(30 \%)$ they found the approach fairly reasonable, and in four cases (1\%) they expressed to be uncertain on this subject. Table 5 presents factors associated with GPs finding delayed prescribing a reasonable strategy.

12 wait-and-see prescriptions from 10 different GPs were issued because of disagreement with the patient. In three of these cases (25\%), the GP found the method very reasonable, as opposed to $71 \%$ when the wait-andsee prescription was issued for other reasons.

In sinusitis, the GPs found delayed prescribing very reasonable in $79 \%$ of the cases. At the opposite, the GPs 
Table 5 GPs opinion of delayed prescribing as a reasonable strategy

\begin{tabular}{|c|c|c|c|c|c|c|c|c|}
\hline & \multicolumn{2}{|c|}{$\begin{array}{c}\text { Total } \\
(\%)\end{array}$} & \multicolumn{2}{|c|}{$\begin{array}{l}\text { Wait-and-see Rx very } \\
\text { reasonable }(\%) \\
(n=210)\end{array}$} & \multicolumn{2}{|c|}{$\begin{array}{l}\text { Wait-and-see } R x \text { not } \\
\text { very reasonable }(\%) \\
(n=94)\end{array}$} & Very reasonable \% & P-value ${ }^{a}$ \\
\hline Upper respiratory tract symptoms and infections & 60 & (20) & 35 & $(17)$ & 25 & (27) & 58 & $0,044^{*}$ \\
\hline Lower respiratory tract infections & 41 & (14) & 20 & (10) & 21 & (22) & 49 & $0,002^{*}$ \\
\hline Ear infections & 65 & $(21)$ & 50 & (24) & 15 & (16) & 77 & 0,12 \\
\hline Sinusitis & 101 & (33) & 80 & (38) & 21 & (22) & 79 & $0,007^{*}$ \\
\hline Acute tonsillitis & 24 & (8) & 17 & (8) & 7 & (7) & 71 & 0,85 \\
\hline Other respiratory diagnoses & 13 & (4) & 8 & $(4)$ & 5 & $(5)$ & 62 & 0,55 \\
\hline \multicolumn{9}{|l|}{ GP's reason for giving delayed prescription $n=304$} \\
\hline Uncertainty about indication for antibiotics & 211 & (69) & 151 & (72) & 60 & (64) & 72 & 0,16 \\
\hline Other reason & 44 & (14) & 34 & (16) & 10 & (11) & 77 & 0,2 \\
\hline Uncertainty about diagnose & 32 & (11) & 22 & (10) & 10 & $(11)$ & 69 & 0,97 \\
\hline Difficulties with follow up & 29 & (10) & 19 & (9) & 10 & (11) & 66 & 0,66 \\
\hline Disagreement with the patient & 12 & $(4)$ & 3 & (1) & 9 & $(10)$ & 25 & $0,001^{*}$ \\
\hline \multicolumn{9}{|l|}{ GP's expectation $n=304$} \\
\hline Patient is likely to take antibiotics & 51 & $(17)$ & 29 & (14) & 22 & (23) & 57 & $0,039^{*}$ \\
\hline Patient is not likely to take antibiotics & 131 & (43) & 100 & (48) & 31 & (33) & 76 & $0,017^{*}$ \\
\hline Uncertain & 122 & $(40)$ & 81 & (39) & 41 & (44) & 66 & 0,41 \\
\hline \multicolumn{9}{|c|}{ GP's impression of patient's antibiotics expectation n = 303 (209/94) } \\
\hline Patient expected antibiotics & 73 & $(24)$ & 47 & (22) & 26 & (28) & 64 & 0,32 \\
\hline Patient did not expect antibiotics & 150 & (50) & 104 & (50) & 46 & (49) & 69 & 0,93 \\
\hline Uncertain & 80 & (26) & 58 & $(28)$ & 22 & (23) & 73 & 0,44 \\
\hline \multicolumn{9}{|l|}{ Grouped age (years) $n=304$} \\
\hline Less than 16 & 100 & (33) & 69 & (33) & 31 & (33) & 69 & \\
\hline $16-59$ & 180 & (59) & 124 & (59) & 56 & $(60)$ & 69 & 0,98 \\
\hline 60 and over & 24 & (8) & 17 & (8) & 7 & (7) & 71 & \\
\hline \multicolumn{9}{|l|}{ Gender $n=304$} \\
\hline Female & 204 & (67) & 139 & (66) & 65 & (69) & 68 & 0,61 \\
\hline Male & 100 & (33) & 71 & (34) & 29 & (31) & 71 & \\
\hline
\end{tabular}

a Pearson chi-square.

found the method very reasonable in $49 \%$ of the lower RTI-cases. The GPs found delayed prescribing more reasonable when they thought the patient would not fill in the prescription $(\mathrm{p}=0.017)$.

\section{Discussion}

\section{Summary of main findings}

General practitioners who have been informed about the use of wait-and-see prescriptions in RTIs, most often use the strategy in cases of acute sinusitis and acute otitis media. These are also the diagnoses for which the GPs find the strategy most reasonable. The reported reason for issuing a wait-and-see prescription is most commonly uncertainty about indication for antibiotics.

Patients receiving a wait-and-see prescription are confident in the decision whether to start taking the medication, and half of the patients report to consume the antibiotics. Feeling very ill, having fever, and being more than 16 years predict consumption of antibiotics, while reporting nasal congestion is negatively associated with consuming antibiotics.

\section{Comparison with existing litterature}

To our knowledge, this is the first survey on delayed prescribing in which different diagnoses are compared, and in which the feasability of the strategy among GPs is measured.

We found that GPs issue wait-and-see prescription most commonly in sinusitis and otitis. When compared to a similar group of GPs in Norway [4], our numbers show an over-representation of sinusitis and otitis, which indicates that patients receiving antibiotics for otitis or sinusitis more often will be instructed to wait than patients receiving antibiotics for other conditions. This may be because otitis and sinusitis are the two conditions for which the Norwegian National Treatment Guidelines recommend "watchful waiting" [16]. A Norwegian prescription study shows that tonsilitis is the 
diagnosis that would most often warrant a prescription for antibiotics, while URTI is at the other extreme [4]. This may explain why patients with tonsilitis in our study felt less ill, and patients with URTI felt more ill, as one could assume that the moderately ill patients with tonsilitis would be given an immediate prescription for antibiotics, and the moderately ill patients with URTI would not be given antibiotics at all.

The first evidence on the advantages of delayed prescribing came from studies on patients with sore throat in the United Kingdom in 1997 [7], and the spreading of this evidence is considered as one of the reasons why antibiotic consumption continued to decrease in the UK from the late 1990s and onwards [25]. However, in our study sore throat is not a condition in which the GPs readily give wait-and-see prescriptions. This may be due to the widespread use of point-of-care streptococcal throat tests in Norwegian general practice [26], and that the GPs let the test results decide whether to prescribe antibiotics.

In our study, $46 \%$ of the patients reported to consume the antibiotics and $86 \%$ reported confidence in deciding whether to take the antibiotics. These findings are similar to Edwards et al, who in a comparable British study [22] found a consumption rate of $53 \%$, and $87 \%$ confident patients. In both studies, fever was found as a predictor for consuming antibiotics. Fever is shown to be the most important cue when parents take treatment decisions on behalf of their sick child [27].

There were some interesting differences regarding patient expectations. Fewer patients in our study expected antibiotics (52\%) compared to the findings of Edwards et al (65\%). This may be due to a real difference in antibiotic expectation, despite similar antibiotic prescription rates in the two countries [3]. Another explanation may be that the GPs in our study to a lesser degree used delayed prescribing as a tool to meet patient expectation for antibiotics. Substantially more patients in our setting expected tests or referral (50\% vs Edwards et al: $2 \%$ ). This indicates that the more widespread use of point-of-care tests in our setting compared to Edwards et al's UK setting [28] has had an influence on patients' expectations.

We found differences in reported consumption rates for the various diagnoses, and the internal variation shows some resemblence with the results achieved in various diagnose-specific RCTs on delayed prescribing; $35 \%$ vs $24-38 \%$ (otitis media) [5,6], $46 \%$ vs $31 \%$ (sore throat) [7], 51\% vs $20-45 \%$ (lower RTI/cough) [8,9], and $57 \%$ vs $48 \%$ (upper RTI/common cold) [10]. The results are understandably not directly comparable, as the methods of issuing delayed prescriptions differ between various studies, the diagnostic criteria varies, and the antibiotic prescription rates [3] and the patients' views on respiratory tract infections show great variance between countries [29]. Nevertheless, the variance between diagnose groups in our study may give valuable information as the prescriptions for various conditions were given in the same setting.

The natural course of otitis in children is a spontaneous recovery after a few days in approximately $80 \%$ of the cases [30], whereas other RTIs may not have this sudden relief. This might explain why ear infection is the diagnose with the lowest pick up rate.

The overall satisfaction with delayed prescribing was high both among GPs and patients. GPs consider overuse of antibiotics a problem [31], and may feel uncomfortable prescribing antibiotics [32]. Thus, there is no surprise that GPs in our study found wait-and-see prescriptions most reasonable among patients who they thought would not pick it up.

Although small numbers, our findings suggest that GPs find delayed prescribing more reasonable in situations of clinical uncertainty rather than in situations where patients demand antibiotics, which is in accordance with the findings in a previous, qualitative study among a similar group of GPs [13].

The GPs found delayed prescribing most reasonable in cases of otitis and sinusitis while the strategy was less valued in cases of upper and lower respiratory tract infections. This may also, as suggested above, be due to the difference in the current understanding and recommended treatment of the various conditions; indication for antibiotics in otitis and sinusitis depends partly, according to Norwegian guidelines, on the duration of symptoms. When it comes to bronchitis and URTI/common cold, the main recommendation is to avoid antibiotics altogether. This might explain why these diagnoses were found less appropriate for delayed prescribing.

\section{Strengths and limitations}

The response rate $(80 \%)$ was relatively high in comparison to a previous study [22]. The aim of this study was not to explore clinical outcomes and safety of the delayed prescribing strategy, and potential differences in treatment outcomes for different diagnoses have not been investigated.

This study does not allow to directly compare the use of wait-and-see prescriptions with the use of prescriptions for antibiotics to be taken immediately, since we have no record of the latter. For illustrative means, we have compared our findings with a reference material of antibiotic prescriptions for RTIs during two winter months.

The participating GPs had agreed to take part in a study on delayed prescribing, and they might hold a more positive view towards the strategy compared to the relatively large group of invited GPs who did not 
participate. However, both high and low prescribers of wait-and-see-prescriptions were represented.

As in all questionnaire surveys, our results depend on the respondents report, and not necessarily on their action. The patient questionnaire and information leaflet were carefully constructed to avoid an impression that not picking up the prescription would be the preferred solution, so as to minimize a desirability bias. Still, the reported antibiotics consumption rate of $46 \%$ may be a underreporting of what actually happened.

The diagnoses referred in this study are the ones chosen by the GPs. We do not know if, and to what extent, diagnostic criteria were followed, and the diagnostic accuracy may have varied between the different GPs.

\section{Conclusion}

Most patients and GPs are satisfied with the delayed prescribing strategy. The patients' age, symptoms and malaise are more important than the diagnosis in predicting antibiotic consumption. The GP's view of the method as a reasonable approach depends on the patient's diagnosis. In our setting, delayed prescribing seems to be a feasible strategy, especially in cases of sinusitis and otitis. Educational efforts to promote delayed prescribing in similar settings should focus on these diagnoses.

\section{Acknowledgements}

We would like to thank Martin Edwards for sharing his patient questionnaire form. We are grateful to the GPs and patients who participated in this study. This study was funded by a research scholarship from The General Practice Research Fund, The Norwegian Medical Association. The funding body had no role in study design, the collection, analysis, and interpretation of data, the writing of the article or the decision to submit it for publication.

\section{Author details}

${ }^{1}$ Antibiotic Center for Primary Care, Department of General Practice, Institute of Health and Society, University of Oslo, P.O.Box 1130 Blindern, N-0318 Oslo, Norway. ${ }^{2}$ Department of Health Management and Health Economics, Institute of Health and Society, University of Oslo, Norway.

\section{Authors' contributions \\ $\mathrm{SH}$ and ML conceived and designed the study. SH collected and analysed the data and wrote the draft manuscript. All authors interpreted the data, critically revised the draft for important intellectual content, prepared the manuscript, and gave final approval of the version to be published.}

\section{Authors' information}

$\mathrm{ML}$ edited and $\mathrm{SH}$ took part in developing the Norwegian National guidelines for antibiotic use in primary health care 2008.

\section{Competing interests}

The authors declare that they have no competing interests.

Received: 1 December 2010 Accepted: 18 May 2011

Published: 18 May 2011

\section{References}

1. Straand J, Rokstad KS, Sandvik H: Prescribing systemic antibiotics in general practice. A report from the More \& Romsdal Prescription Study. Scand J Prim Health Care 1998, 16(2):121-127.
2. Arroll B: Antibiotics for upper respiratory tract infections: an overview of Cochrane reviews. Respir Med 2005, 99(3):255-261.

3. Goossens $H$, Ferech M, Vander SR, Elseviers M: Outpatient antibiotic use in Europe and association with resistance: a cross-national database study. Lancet 2005, 365(9459):579-587.

4. Gjelstad S, Dalen I, Lindbaek M: GPs' antibiotic prescription patterns for respiratory tract infections - still room for improvement. Scand J Prim Health Care 2009, 27(4):208-215.

5. Little P, Gould C, Williamson I, Moore M, Warner G, Dunleavey J: Pragmatic randomised controlled trial of two prescribing strategies for childhood acute otitis media. BMJ 2001, 322(7282):336-342.

6. Spiro DM, Tay KY, Arnold DH, Dziura JD, Baker MD, Shapiro ED: Wait-andsee prescription for the treatment of acute otitis media: a randomized controlled trial. JAMA 2006, 296(10):1235-1241.

7. Little P, Williamson I, Warner G, Gould C, Gantley M, Kinmonth AL: Open randomised trial of prescribing strategies in managing sore throat. $B M J$ 1997, 314(7082):722-727.

8. Dowell J, Pitkethly M, Bain J, Martin S: A randomised controlled trial of delayed antibiotic prescribing as a strategy for managing uncomplicated respiratory tract infection in primary care. Br J Gen Pract 2001, 51(464):200-205

9. Little P, Rumsby K, Kelly J, Watson L, Moore M, Warner G, et al: Information leaflet and antibiotic prescribing strategies for acute lower respiratory tract infection: a randomized controlled trial. JAMA 2005, 293(24):3029-3035.

10. Arroll B, Kenealy $T$, Kerse $N$ : Do delayed prescriptions reduce the use of antibiotics for the common cold? A single-blind controlled trial. J Fam Pract 2002, 51(4):324-328.

11. Spurling GK, Del Mar CB, Dooley L, Foxlee R: Delayed antibiotics for respiratory infections. Cochrane Database Syst Rev 2007, , 3: CD004417.

12. Petursson P: GPs' reasons for "non-pharmacological" prescribing of antibiotics. A phenomenological study. Scand J Prim Health Care 2005, 23(2):120-125.

13. Høye S, Frich JC, Lindbaek M: Delayed prescribing for upper respiratory tract infections: a qualitative study of general practitioners' views and experiences. Br J Gen Pract 2010, 60(581):907-912.

14. Little $P$ : Delayed prescribing of antibiotics for upper respiratory tract infection. BMJ 2005, 331(7512):301-302.

15. Prescribing of antibiotics for self limiting respiratory tract infections in adults and children in primary care. National Institute for Health and Clinical Excellence; 2008, Clinical Guideline 69.

16. The Directorate of Health, The antibiotic center for primary helath care: [National guidelines for antibiotic use in primary health care]. Oslo: The Directorate of Health; 2008.

17. STRAMA, Medical Products Agency: [Diagnostics, treatment and follow-up of acute otitis media (AOM) - new recommendation]. Information from the Medical Products Agency 2010, 21(5):13-24.

18. Gjelstad S, Fetveit A, Straand J, Dalen I, Rognstad S, Lindbaek M: Can antibiotic prescriptions in respiratory tract infections be improved? A cluster-randomized educational intervention in general practice-the Prescription Peer Academic Detailing (Rx-PAD) Study [NCT00272155]. BMC Health Serv Res 2006, 6:75.

19. McDermott L, Yardley L, Little P, Ashworth M, Gulliford M, Research Team: Developing a computer delivered, theory based intervention for guideline implementation in general practice. BMC Fam Pract 2010, 11(1):90.

20. Simpson SA, Butler CC, Hood K, Cohen D, Dunstan F, Evans MR, et al: Stemming the Tide of Antibiotic Resistance (STAR): a protocol for a trial of a complex intervention addressing the 'why' and 'how' of appropriate antibiotic prescribing in general practice. BMC Fam Pract 2009, 10:20.

21. Arroll B, Goodyear-Smith F, Thomas DR, Kerse N: Delayed antibiotic prescriptions: what are the experiences and attitudes of physicians and patients? J Fam Pract 2002, 51(11):954-959.

22. Edwards M, Dennison J, Sedgwick P: Patients' responses to delayed antibiotic prescription for acute upper respiratory tract infections. $\mathrm{Br} J$ Gen Pract 2003, 53(496):845-850.

23. Grol $R$, Wensing $M$ : What drives change? Barriers to and incentives for achieving evidence-based practice. Med J Aust 2004, 180(6 Suppl) S57-S60.

24. Gjelstad S, Dalen I, Lindbaek M: GPs' antibiotic prescription patterns for respiratory tract infections-still room for improvement. Scand J Prim Health Care 2009, 27(4):208-215 
25. Sharland M, Kendall H, Yeates D, Randall A, Hughes G, Glasziou P, et al: Antibiotic prescribing in general practice and hospital admissions for peritonsillar abscess, mastoiditis, and rheumatic fever in children: time trend analysis. BMJ 2005, 331(7512):328-329.

26. Fagan M: [ls otitis and tonsillitis handled in the same way within normal working hours and out-of-hours?]. Tidsskr Nor Laegeforen 2008, 128(20):2340-2342

27. Lagerlov P, Loeb M, Slettevoll J, Lingjaerde OC, Fetveit A: Severity of illness and the use of paracetamol in febrile preschool children; a case simulation study of parents' assessments. Fam Pract 2006, 23(6):618-623.

28. Butler CC, Simpson S, Wood F: General practitioners' perceptions of introducing near-patient testing for common infections into routine primary care: a qualitative study. Scand J Prim Health Care 2008, 26(1):17-21.

29. Deschepper R, Vander Stichele RH, Haaijer-Ruskamp FM: Cross-cultural differences in lay attitudes and utilisation of antibiotics in a Belgian and a Dutch city. Patient Educ Couns 2002, 48(2):161-169.

30. Glasziou PP, Del Mar CB, Sanders SL, Hayem M: Antibiotics for acute otitis media in children. Cochrane Database Syst Rev 2004, , 1: CD000219.

31. Simpson SA, Wood F, Butler CC: General practitioners' perceptions of antimicrobial resistance: a qualitative study. J Antimicrob Chemother 2007, 59(2):292-296.

32. Bradley CP: Uncomfortable prescribing decisions: a critical incident study BMJ 1992, 304(6822):294-296.

\section{Pre-publication history}

The pre-publication history for this paper can be accessed here: http://www.biomedcentral.com/1471-2296/12/34/prepub

doi:10.1186/1471-2296-12-34

Cite this article as: Høye et al:: Use and feasibility of delayed

prescribing for respiratory tract infections: A questionnaire survey. BMC

Family Practice 2011 12:34.

\section{Submit your next manuscript to BioMed Central} and take full advantage of:

- Convenient online submission

- Thorough peer review

- No space constraints or color figure charges

- Immediate publication on acceptance

- Inclusion in PubMed, CAS, Scopus and Google Scholar

- Research which is freely available for redistribution

Submit your manuscript at www.biomedcentral.com/submit 